\title{
PREVALENCE OF PATHOLOGICAL GAMBLING AMONG ALCOHOL ADDICTS IN OUTPATIENT TREATMENT IN THE CITY OF ZAGREB: A CROSS-SECTIONAL STUDY
}

\author{
Davor Bodor ${ }^{1}$, Neven Ricijaš², Zoran Zoričić ${ }^{3}$, Dora Dodig Hundrić ${ }^{2}$ \& Igor Filipčici ${ }^{1,4,5}$ \\ ${ }^{I}$ Psychiatric Hospital "Sveti Ivan", Zagreb, Croatia \\ ${ }^{2}$ University of Zagreb, Faculty of Education and Rehabilitation Sciences, Zagreb, Croatia \\ ${ }^{3}$ University Clinical Hospital Sestre Milosrdnice, Zagreb, Croatia \\ ${ }^{4}$ Faculty of Medicine, Josip Juraj Strossmayer University of Osijek, Osijek, Croatia \\ ${ }^{5}$ School of Medicine, University of Zagreb, Zagreb, Croatia
}

received: 15.5.2017;

revised: 30.10.2017;

accepted: 14.12 .2017

\begin{abstract}
SUMMARY
Background: Various types of addictions often co-occur, particularly substance and behavioral ones, which affects the clinical course of mental health disorders as well as the efficacy of therapy and rehabilitation efforts. The present study aims to explore gambling activities and possible gambling addiction among alcoholics in an outpatient treatment in the city of Zagreb.

Subjects and methods: Gambling activities were assessed in 140 members of alcohol addiction clubs in the City of Zagreb (Croatia). Participants were undergoing treatment after being diagnosed by their psychiatrist with alcohol dependence syndrome based on ICD-10 criteria. Intensity of gambling-related problems was measured using the South Oaks Gambling Screen (SOGS), while intensity of alcohol addiction was assessed using DSM-5 diagnostic criteria for alcohol use disorder. All instruments were selfreport forms and were completed using pen and paper in a group context during outpatient treatment.

Results: Pathological gambling was more prevalent in this clinical subsample than in general populations analysed in other studies. Alcohol addicts showing problematic or pathological gambling behaviors tended to play more highly addictive games (sports betting, slot machines, roulette). However, intensity of gambling-related problems did not correlate significantly with the intensity of alcohol addiction.

Conclusion: These results confirm studies from other countries showing higher prevalence of problematic and pathological gambling among alcohol addicts than in the general population. Gambling behavior in our sample more often involved games with greater addictive potential. These findings suggest that alcohol addicts should be systematically screened for problematic and pathological gambling, which may improve therapeutic efficacy and rehabilitation, as well as reduce relapse in addictive behavior in general.
\end{abstract}

Key words: gambling - gambling disorder - alcohol use disorder - SOGS - DSM-5

\section{INTRODUCTION}

Alcohol addiction is a significant, widespread public health problem, with harmful use of alcohol leading to approximately 3.3 million deaths each year (WHO 2014). The World Health Organisation estimates that 3$4 \%$ of the Croatian population (150-200,000 people) are alcohol addicts (WHO 2014). Alcohol addiction is diagnosed on the basis of cognitive and physiological changes induced by repeated alcohol consumption, and addicts continue to drink despite awareness of the negative consequences, such as when they wish to alleviate the physiological and psychological effects of abstinence (WHO 1992, APA 2013).

Alcohol addiction often co-occurs with other mental disorders, which can strongly influence the clinical course of alcohol addiction as well as the efficacy of therapy and rehabilitation efforts. Mental disorders occur in $30-75 \%$ of alcohol addicts, in contrast to 15 $20 \%$ of the general population (Grant et al. 2004, Mann et al. 2004, Wüstoff et al. 2011, Sanchez et al. 2012). Conversely, more than $30 \%$ of patients diagnosed with a mental disorder also meet the criteria for abusing or being addicted to psychoactive substances, including alcohol (Błachut et al. 2013). The most frequent psychiatric comorbidities in alcohol addicts are affective and anxiety disorders: alcoholics are three times more likely to develop an anxiety disorder and four times more likely to develop major depressive disorder than the general population (Agosti \& Levine 2006, Anthenelli 2010).

Alcohol addiction can co-occur not just with psychiatric disorders but also with behavioural addictions, of which gambling addiction is the only one to be formally recognised. Patients with behavioural addictions resemble alcohol addicts in that they also manifest cravings, compulsive behaviour, physiological and psychological symptoms of abstinence, loss of control, development of tolerance and susceptibility to psychotropic effects (Alavi et al. 2010). Gambling-related problems, first referred to as pathological gambling and classified as an impulse control disorder in the Diagnostic and Statistical Manual of Mental Disorders (DSM-III 1980; DSM-IV 1994), have since been renamed gambling 
disorder and assigned to addiction disorders (DSM-5 2013). This puts gambling-related problems in the same category as addictions to psychoactive substances (APA 2013). This reclassification reflects similarities between gambling addiction and substance addiction in terms of clinical picture, genetic risk factors, therapeutic interventions, as well as neurocognitive and neurobiological changes (Hasin et al. 2013, et al. 2011). Welte et al. (2001) reported significant correlation between the presence of alcohol addiction and of pathological gambling, and they further showed that greater daily alcohol consumption was associated with more intense and frequent gambling. In a population study involving 14,934 people, El-Guebaly et al. (2006) concluded that people who abuse alcohol or are addicted to it are 2.9 times more likely to develop moderate or heavy gambling problems. In a study of addicts receiving inpatient treatment for addiction to alcohol or other psychoactive substances, $15 \%$ met the diagnostic criteria of gambling disorder at some point during their lives, and $10.9 \%$ met the criteria at the time of treatment (Cowlishaw et al. 2014).

One study of alcohol addicts receiving outpatient treatment reported that approximately $19 \%$ manifested characteristics of problematic gambling during the study, based on the South Oaks Gambling Screen (SOGS) questionnaire criteria (Sellman et al. 2002), while 4\% met the DSM-IV criteria of pathological gambling. These prevalence rates are much higher than the $0.5-2 \%$ reported for problematic and pathological gambling in the general population (Petry et al. 2005, Kessler et al. 2008, Hodgins et al. 2011, Cowlishaw et al. 2014).

So far, evidence for comorbidity of pathological gambling and alcoholism has come mainly from studies in Western Europe, North America and Australia. Whether the same holds for populations in other parts of the world is unclear. For example, we are unaware of studies on gambling behaviours or prevalence of pathological gambling among alcohol addicts in central Europe, including Croatia. Establishing a linkage between gambling and alcohol problems in a given population may enhance clinicians' ability to personalise therapy and lead to more effective treatment, lower treatment costs and lower relapse rates (Winter \& Cushner 2003, Grant et al. 2006). Integrating diagnostic tests for pathological gambling into treatment programmes for alcohol addicts may reduce the intensity of gamblingand alcohol-related problems (Kausch 2003).

Considering all the results from aforementioned foreign studies, this is the first cross-sectional study conducted in Croatia, which aims to explore gambling activities and possible gambling addiction among alcoholics in an outpatient treatment in the city of Zagreb. Using self-assessment instruments, prevalence and frequency of gambling, as well as levels of pathological gambling were measured. Correlations between intensity of alcoholism and intensity of gambling-related problems were also explored.

\section{SUBJECTS AND METHODS}

\section{Study participants}

The study involved 140 individuals (116 men, 24 women) who had been diagnosed with alcohol dependence syndrome based on ICD-10 criteria and who were active members of clubs for treatment of alcohol addiction in the City of Zagreb (Croatia). These individuals attended 17 of the 78 clubs registered in the city. Alcohol addicts with severe physical disease, psycho-organic syndrome, psychotic disorders or primary deeper intelligence impairment were excluded from the study. Participants were informed about the main objective of the study, and they gave written informed consent.

Participant age ranged from 25 to 77 years (Mage $=$ 53.09, SDage = 11.09). Of the 140 subjects, 9 had completed only primary school; 98 , secondary school; 14, higher school; 13, university; and 5, a sciencerelated master's or doctoral degree. One participant had stopped education during primary school. With regards to employment status, of the 140 participants, 67 participants had steady employment, 49 were retired, 19 were unemployed, and 5 were temporarily employed or working illegally. Most participants (81) were married; 23, single; 22, divorced; 9, widowed; and 5 in a serious relationship but not living together. Most participants (106) had one or more children, of which $25 \%$ had one; $37.1 \%$, two; $11.4 \%$, three; $1.4 \%$, four; and $0.7 \%$, eight. The remaining 34 participants had no children.

\section{Assessment instruments}

\section{Check List of Gaming Activities}

This checklist is a modified form of the Croatianlanguage Questionnaire on Gambling Activities (Ricijaš et al. 2011), which asks respondents about the frequencies with which they engage in various types of gambling. Five types of gambling are considered formal because they are provided by licensed, regulated operators: lotto, scratch cards, sports betting, slot machines and roulette. The sixth type is informal: playing cards for money, such as with friends. Participants indicate whether and how often they engage in each type of gambling activity using a 7point scale $(0=$ never, $1=$ once per year or less, $2=a$ few times per year, $3=$ once or twice per month, $4=$ once per week, $5=$ a few times per week, $6=$ every day).

\section{South Oaks Gambling Screen (SOGS)}

SOGS is a self-report measure based on DSM-3 criteria for pathological gambling. It is designed to distinguish among three levels of gambling behaviour: (1) social, (2) at-risk/problematic or (3) pathological (Lesieur and Blume, 1987). SOGS has become a gold standard instrument for self-assessment of gamblingrelated problems over the last 30 years (Barrault \& 
Varescon 2012, Marazziti et al. 2014, Ciccareli et al. 2016, Jauregui et al. 2016). The total score indicates the level of gambling-related psychosocial problems, with higher scores corresponding to more intense problems. SOGS consistently shows good psychometric characteristics across different cultures (Alessi et al. 2003, Stinchfield 2002, Stinchfield 2003, Petry 2005).

The questionnaire consists of 26 statements, 20 of which are scored in order to diagnose the respondent and classify his or her level of psychosocial problems. Subjects respond to each statement with "yes" (1 point) or "no" (0 point), so total scores can range from 0 to 20. Statements include: "Have you ever felt like you would like to stop betting money on gambling, but didn't think you could?", "Have you ever claimed to be winning money while gambling, even though you were actually losing money?", and "Have you ever borrowed from someone and not paid them back as a result of your gambling?" The overall score is used to classify the level or intensity of gambling-related problems as none (0 points), at-risk/problematic (1-4 points), or pathological (5+ points). The total SOGS score in our sample ranged from 0 to 17 (MSOGS $=1.16$; $\mathrm{SDSOGS}=9.18)$, and the scale showed high internal consistency (Cronbach's alpha $\alpha=0.930$ ).

\section{DSM-5 Scale for Alcohol Use Disorder - Self-report Version}

This self-assessment questionnaire is based on DSM-5 (2013) criteria for alcohol use disorder and is designed to assess behaviours and emotions (symptoms) before the subject begins treatment. Subjects respond to 11 statements with "no" (0 point) or "yes" (1 point). Statements include "Have you ever had times when you ended up drinking more, or longer than you intended?", "Have you experienced craving - a strong need, or urge, to drink?", and "Have you more than once gotten into situations while or after drinking that increased your chances of getting hurt (such as driving, swimming, using machinery, walking in a dangerous area, or having unsafe sex)?" The total score, which can range from 0 to 11 , serves as the basis for classifying the severity of alcohol addiction as mild (2-3 points), moderate (4-5 points) or severe $(6+$ points $)$. The total score in our sample ranged from 3 to 11 , and the average score was high (MDSM-5=8.25; SDDSM-5=8.49). The instrument showed good internal consistency in our study (Cronbach's alpha $\alpha=0.839$ ). In other studies, these DSM-5 criteria have shown sensitivity and specificity exceeding $85 \%$, and they show excellent agreement with the previous DSM-IV-TR criteria (APA 2013, Compton et al. 2013).

\section{Data processing methods}

Results were reported using response frequencies, while comparisons between groups were conducted using the Kruskal-Wallis test, followed by the Mann-Whitney
$\mathrm{U}$ test as a post-hoc test (with Bonferroni correction), and counting for effect sizes based on the formula for nonparametric statistics $(\mathrm{r}=\mathrm{Z} / \mathrm{SQRT}(\mathrm{N}))$.

\section{Assessment procedure and ethics}

Study participants were invited to fill out all survey instruments during their routine group treatment sessions at their usual club for alcohol treatment. The questionnaire was anonymous, and subjects were encouraged to answer honestly. Participants were also told that they could stop filling out the questionnaires at any time, without having to explain themselves or suffer any consequences. The study was approved by the Association of Clubs of Treated Alcoholics and by the Ethics Committee of the School of Dental Medicine of the University of Zagreb, and it was carried out in accordance with the Helsinki Declaration.

\section{RESULTS}

Analysis of self-reported life-time prevalence of different gambling activities (Table 1) showed that participants had the most experience playing lotto (59.3\%) and scratch cards $(36.4 \%)$, followed by sports betting (27.9\%). In general, most participants who ever played lottery games did not play them very often. As expected, sports betting was the most frequently played game, which $12.2 \%$ of participants played regularly (at least once per week). This is a notable result because sports betting is considered to have much higher addictive potential than lottery games and therefore to pose a greater risk for the development of pathological gambling (Ricijaš et al. 2015).

Based on total SOGS scores, 109 participants (77.9\%) had no gambling-related problems, whereas 17 $(12.1 \%)$ met the criteria for at-risk/problematic gambling, and $14(10.0 \%)$ met the criteria for pathological gambling. The latter two prevalences are much larger than the corresponding prevalences in the general population, which usually range between $0.5 \%$ and $2 \%$, depending on the instruments and assessment systems used (Petry et al. 2005, Kessler et al. 2008, Hodgins et al. 2011, Cowlishaw et al. 2014). Systematic studies of problem gambling based on the SOGS or other selfassessment instruments have not been conducted on the general population in Croatia. Therefore it is not possible to directly compare gambling frequencies in our clinical population with those in the general population. Nevertheless, one study about habits and behavior in the general Croatian population aged 18-65 (Glavak Tkalić \& Miletić 2012) found that 2.5\% of population reported having had gambling-related problems at one point in their lives. This result is in accordance with other Western studies mentioned above. Whatever the comparison with the general population, our results indicate that nearly one quarter of our clinical population of alcohol addicts also had gambling-related problems. 
Table 1. Frequencies (\%) of various gambling activities $(\mathrm{N}=140)$

\begin{tabular}{lccccccc}
\hline Activity & Never & $\begin{array}{c}\text { 1x per year } \\
\text { or less }\end{array}$ & $\begin{array}{c}\text { A few times } \\
\text { per year }\end{array}$ & $\begin{array}{c}\text { 1-2x per } \\
\text { month }\end{array}$ & 1x per week & $\begin{array}{c}\text { A few times } \\
\text { per week }\end{array}$ & Everyday \\
\hline Lotto & 40.7 & 14.7 & 25.0 & 8.6 & 7.9 & 3.6 & 0.0 \\
Scratch cards & 63.6 & 20.0 & 11.4 & 3.6 & 0.7 & 0.7 & 0.0 \\
Sports betting & 72.1 & 5.7 & 7.1 & 2.9 & 4.3 & 4.3 & 3.6 \\
Slot machines & 84.3 & 7.9 & 5.0 & 0.7 & 0.0 & 1.4 & 0.7 \\
Roulette & 92.1 & 4.3 & 2.9 & 0.7 & 0.0 & 0.0 & 0.0 \\
Playing cards for money & 92.9 & 6.4 & 0.0 & 0.0 & 0.0 & 0.0 & 0.0 \\
\hline
\end{tabular}

Table 2. Differences in the frequency of gambling based on SOGS categories of gambling-related problems $(\mathrm{N}=140)$

\begin{tabular}{|c|c|c|c|c|c|}
\hline Gambling activity & Category & KW-MR & $\mathrm{KW} \chi^{2}$ & MWU & $\mathrm{r}$ \\
\hline Lotto & $\begin{array}{l}\text { NP } \\
\text { RP } \\
\text { PG }\end{array}$ & $\begin{array}{r}64.17 \\
82.88 \\
104.79\end{array}$ & $15.61 * *$ & $\mathrm{NP}<\mathrm{RP} * * *$ & 0.31 \\
\hline Scratch cards & $\begin{array}{l}\text { NP } \\
\text { RP } \\
\text { PG }\end{array}$ & $\begin{array}{l}66.19 \\
84.59 \\
86.96\end{array}$ & $7.62 *$ & & \\
\hline Sports betting & $\begin{array}{l}\text { NP } \\
\text { RP } \\
\text { PG }\end{array}$ & $\begin{array}{r}62.99 \\
93.03 \\
101.64\end{array}$ & $27.64 * * *$ & $\begin{array}{l}\mathrm{NP}<\mathrm{RP}^{* * * *} \\
\mathrm{NP}<\mathrm{PG}^{* * *}\end{array}$ & $\begin{array}{l}0.33 \\
0.37\end{array}$ \\
\hline Slot machines & $\begin{array}{l}\text { NP } \\
\text { RP } \\
\text { PG }\end{array}$ & $\begin{array}{r}63.97 \\
83.32 \\
105.75\end{array}$ & $37.69 * * *$ & $\begin{array}{l}\mathrm{NP}<\mathrm{RP}^{* * *} \\
\mathrm{NP}<\mathrm{PG}^{* * *}\end{array}$ & $\begin{array}{l}0.30 \\
0.52\end{array}$ \\
\hline Roulette & $\begin{array}{l}\text { NP } \\
\text { RP } \\
\text { PG }\end{array}$ & $\begin{array}{l}67.00 \\
72.94 \\
94.82\end{array}$ & $27.16^{* * *}$ & $\mathrm{NP}<\mathrm{PG}^{* * *}$ & 0.45 \\
\hline Playing cards for money & $\begin{array}{l}\text { NP } \\
\text { RP } \\
\text { PG } \\
\end{array}$ & $\begin{array}{l}86.10 \\
73.68 \\
85.36 \\
\end{array}$ & $11.88^{* *}$ & $\mathrm{NP}<\mathrm{PG}^{* * *}$ & 0.29 \\
\hline
\end{tabular}

Abbreviations: KW-MR=Kruskal-Wallis mean rank; KW=Kruskal-Wallis $\chi^{2} ; \quad$ MWU=Mann-Whitney U test;

$\mathrm{NP}=$ no gambling-related problems; $\mathrm{RP}=$ at-risk/problematic gambling; $\mathrm{PG}=$ pathological gambling; $\mathrm{r}=$ effect size; significance (with Bonferroni correction on Mann-Whitney) ${ }^{*} \mathrm{p}<0.05,{ }^{*} \mathrm{p}<0.01,{ }^{* * *} \mathrm{p}<0.001$

Next we analysed differences in frequencies of the various types of gambling activities among three subgroups of participants (Table 2): (1) those with no gambling-related problems (NP), (2) those showing atrisk/problematic intensity of gambling-related problems (RP), and (3) those showing pathological intensity of gambling problems (PG). Our primary goal was to explore whether certain gambling activities might be more closely associated with pathological gambling. Our secondary goal was to assess the convergent validity of SOGS scores in our sample, since participants who show symptoms of pathological gambling are expected to gamble more frequently. As expected, Kruskal-Wallis test showed differences between subgroups. After performing Mann-Whitney U-test as post-hoc test (with Bonferroni correction), only significant differences were presented in Table 2, together with effect sizes that range from 0.30 to 0.52 . Effect sizes were greatest for the three formal gambling activities considered to be highly addictive: (1) sports betting, (2) slot machines and (3) roulette. There are no significant differences in the intensity of playing scratch cards, which may reflect the lower addictive potential of this activity.
On the DSM-5 self-report scale, all participants described behavioural and emotional experiences during the pre-treatment period. This is consistent with the fact that an inclusion criterion of the study was for a psychiatrist to have determined that a patient met the ICD-10 diagnostic criteria for alcohol dependency syndrome. Thus, this self-report method also provides us with a subjective perception of participants' insight into their own problems. Most participants (72.9\%) believed that they met the criteria for severe alcoholism, $15.0 \%$ for moderate alcoholism, and $8.6 \%$ for mild alcoholism. Three participants $(3.6 \%)$ believed that they had no alcohol-related problems at the start of treatment, a striking finding from a therapeutic perspective.

Given our observation of correlations between gambling activities and alcohol addiction, we wanted to know whether the intensity of gambling-related problems correlated with that of alcohol-related problems. Therefore we explored correlations between total scores on the SOGS and DSM-5 scales. No significant correlation was detected by Pearson correlation analysis $(\mathrm{r}=0.096, \mathrm{p}>0.050)$. In accordance with that result and for more descriptive purposes, Table 3 presents crosstable comparison between prevalences of different SOGS 
Table 3. Comparison between prevalences of different SOGS categories of gambling problems with DSM-5 categories of alcohol use disorder $(\mathrm{N}=140)$

\begin{tabular}{|c|c|c|c|c|c|}
\hline \multirow{2}{*}{\multicolumn{2}{|c|}{ Gambling related problems (SOGS) }} & \multicolumn{4}{|c|}{ Intensity of alcohol use disorder (DSM-5) } \\
\hline & & \multirow{2}{*}{$\begin{array}{c}\text { None } \\
3\end{array}$} & \multirow{2}{*}{$\begin{array}{c}\text { Mild } \\
11\end{array}$} & \multirow{2}{*}{$\begin{array}{c}\text { Moderate } \\
18\end{array}$} & \multirow{2}{*}{$\frac{\text { Severe }}{77}$} \\
\hline No problem & $\mathrm{n}$ & & & & \\
\hline & $\%$ & 2.8 & 10.1 & 16.5 & 70.6 \\
\hline \multirow{2}{*}{ At-risk/problematic } & $\mathrm{n}$ & 1 & 1 & 2 & 13 \\
\hline & $\%$ & 5.9 & 5.9 & 11.8 & 76.5 \\
\hline \multirow[t]{2}{*}{ Pathological } & $\mathrm{n}$ & 1 & 0 & 1 & 12 \\
\hline & $\%$ & 7.1 & 0.0 & 7.1 & 85.7 \\
\hline
\end{tabular}

categories of gambling problems with DSM-5 categories of alcohol use disorders. As shown, the prevalences of the different SOGS categories of gambling related problems were similar among patients with severe alcohol use disorder, ranging from $70.6 \%$ to $85.7 \%$; and they were similar among patients with moderate alcohol use disorder, ranging from $7.1 \%$ to $16.5 \%$.

\section{DISCUSSION}

This is the first cross-sectional study conducted in Croatia that showed higher prevalence of problematic and pathological gambling in the clinical subsample of alcohol addicts in outpatient treatment than in the general population. Gambling behaviour in our sample showed higher frequency of involvement in games with greater addictive potential. As mentioned before, no systematic studies of problem gambling based on the SOGS or other self-assessment instruments have been conducted on the general, or representative adult population in Croatia, which unable us to directly compare gambling frequencies in our clinical population with those in Croatian general population. At the same time, prevalence rate of $12.1 \%$ for at risk/problem gambles and $10.0 \%$ for pathological gamblers in this clinical sample seems much higher than any prevalence rates in general population based on international research, as well as indications from study performed by Glavak Tkalić \& Miletić (2012) stating how 2.5\% of Croatian population reported having had gambling-related problems at one point in their lives. In fact, the prevalence of problem/pathological gambling in our outpatient sample was closer to that reported for inpatients in other studies (Cowlishaw et al. 2014, Sellman et al. 2002, Lesieur \& Blum 1986), which is higher than for outpatient treatment patients.

In this way, our study extends to central Europe previous observations of the frequent comorbidity of pathological gambling and alcohol addiction, as well as previous reports of a correlation between gambling in general and addiction to psychoactive substances. This strengthens the argument for addiction syndrome, which postulates a shared aetiology (perhaps at least partly genetic) for addiction to gambling and addiction to psychoactive substances (Schaffer et al. 2004, Slutske et al. 2000, Blum et al. 2000). Our results also strengthen previous suggestions that one type of addictive behaviour (such as alcoholism) increases the risk of developing a second type of addiction (such as gambling addiction). For example, alcohol addiction may render an individual more prone to engage in risk behaviours such as gambling, while gambling, in turn, may have harmful cumulative psychosocial consequences for an alcohol addict, increasing risk of more severe alcohol-related problems or relapse (Punt et al. 1996).

This has potentially profound implications for treating alcohol addiction. As first pointed out nearly three decades ago, treating alcohol addicts only for alcohol abuse is insufficient, and such addicts suffer greater problems and face worse prognosis than patients with only one mental health disorder (Bukstein et al. 1989). Our study and other work argue strongly for systematically screening patients with alcohol and substance use disorder for problematic/pathological gambling as part of routine clinical procedures.

Our results provide additional detail into the gambling problems faced by alcohol addicts receiving outpatient treatment. We found that the subgroup of addicts engaging in gambling activities tended to engage in more addictive activities, including sports betting, slot machines and roulette. This may indicate a "vicious cycle" in which alcohol addicts are at higher risk of gambling in general, and those who develop gamblingrelated problems are more likely to continue or progress to pathological gambling because they engage in gambling activities that are more highly addictive; to make matters worse, alcohol is usually readily available at many gambling venues. This may help explain why alcohol addicts appear to be at higher risk of pathological gambling than the general population. Highly addictive gambling activities are associated with higher risk of creating addiction as well as psychosocial problems. These activities may be more highly addictive for gamblers because of their higher frequency, greater self-perception of skill, greater impact on cognitive distortions, and greater ability to manipulate stakes, as well as certain characteristics of the environment where the activity takes place (Ricijaš \& Milun 2016). Regardless of the mechanisms that make certain gambling activities more addictive than others, our results may help identify the potentially most damaging activities to screen for and treat among alcohol addicts during outpatient therapy. 
Although we provide strong evidence of a correlation between the occurrence of gambling addiction and the frequency of gambling, we did not observe a correlation between the intensity of the two addictions (gambling and alcohol addiction), in contrast to earlier studies on multimorbidity of psychiatric disorders, where the occurrence of comorbid conditions is associated with greater intensity of the primary problem (Angst et al. 2002, Brooner et al. 1997). We could also attribute such results to study limitations, namely a convenient sample and self-report measurement. Therefore, in the future, this finding should be confirmed in larger-scale studies, preferably longitudinal ones involving different populations and clinical subgroups, using combination of clinical professional assessment with self-assessments of patients. If verified, our result may mean that addiction to alcohol and addiction to gambling may share similar mechanism(s) of onset, reflected in similar profiles of overall symptomatology, but not necessarily similar mechanisms of progression or of variable symptomatology differing from addict to addict. One of the reasons may also be that alcohol addicts receiving outpatient treatment usually show a lower prevalence of gambling problems and psychiatric comorbidity than those receiving inpatient treatment (Finney et al. 1996). Whether such comorbidities potentiate the primary addiction in a proportional or all-or-nothing fashion should be investigated in future work.

The present study presents the first detailed insights into gambling comorbidity among alcohol addicts in Zagreb and, in the process, complements the global research literature on this question. Our findings, like those in several other countries, point to the need to personalise treatment for alcohol addicts in a way that takes into account their greater risk of engaging in gambling activities to a problematic or even pathological degree. It would be interesting to verify the present findings by adopting a 'reverse design' in which the prevalence of alcohol addiction is explored in a clinical sample of gambling addicts. Future work should also examine potential causal relationships between gambling and alcohol addiction using a longitudinal design, thereby directly testing for the existence of addiction syndrome.

\section{CONCLUSION}

Results of this study indicate high prevalence of problematic and pathological gambling among alcohol addicts, with their frequent involvement in addictive gambling activities (spots betting, slot machines and roulette games). Nevertheless, we did not find evidence of a correlation between the intensity of alcohol addiction and intensity of gambling-related problems. These findings may have important practical implications for structuring an integrated therapeutic approach to treat alcohol addicts.

\section{Acknowledgements:}

Authors would like to thank all participants, members of alcohol addiction clubs in the City of Zagreb (Croatia), for their time and effort to voluntarily participate in this study.

\section{Conflict of interest: None to declare.}

\section{Contribution of individual authors:}

Davor Bodor was involved with study design, data collection, data interpretation, and manuscript preparation.

Neven Ricijaš was involved with the study design, statistical analyses and data interpretation, manuscript preparation and performed multiple edits of the manuscript drafts.

Zoran Zoričić was involved with the study design and reviewed the manuscript drafts.

Dora Dodig Hundrić assisted in literature research, statistical analyses and in manuscript preparation.

Igor Filipčić reviewed and edited draft manuscript.

\section{References}

1. Agosti $V$ \& Levine FR: The effects of alcohol and drug dependence on the course of depression. Am J Addict 2006; 15:71-5

2. Alessi SM \& Petry NM: Pathological gambling severity is associated with impulsivity in a delay discounting procedure. Behav Process 2003; 64:345-54

3. American Psychiatric Association: Diagnostic and Statistical Manual of Mental Disorders (5th ed.). VA: American Psychiatric Publishing, Arlington, 2013

4. Anthenelli RM: Focus on comorbid mental health disorders. Alcohol Res Health 2010; 33:109-17

5. Barrault $S$ \& Varescon I: Psychopathology in online pathological gamblers: A preliminary study. Encephale 2012; 38:156-63

6. Błachut M, Badura-Brzoza K, Jarzab M, Gorczyca P \& Hese RT: Podwójna diagnoza u osób uzależnionych lub szkodliwie używajacych substancji psychoaktywnych. Psychiatr Pol 2013; 47:335-52

7. Blum K, Braverman ER, Holder JM, Lubar JF, Monastra $V J$, Miller $D$ et al: Reward deficiency syndrome: $A$ biogenetic model for the diagnosis and treatment of impulsive, addictive, and compulsive behaviors. J Psychoactive Drugs 2000; 32:1-112

8. Brooner RK, King VL, Kidorf $M$, Schmidt $C W$ \& Bigelow GE: Psychiatric and substance use comorbidity among treatment-seeking opioid abusers. Arch Gen Psychiatry 1997; 54:71-80

9. Bukstein $O G$, Brent DA \& Kaminer Y: Comorbidity of substance abuse and other psychiatric disorders in adolescents. Am J Psychiatry 1989; 146:1131-41

10. Chou KL \& Afifi TO: Disordered (pathologic or problem) gambling and Axis I psychiatric disorders: Results from the National Epidemiologic Survey on Alcohol and Related Conditions. Am J Epidemiol 2011; 173:1289-97 
11. Ciccarelli M, Nigro G, Griffiths $M D$, Cosenza $M \&$ D'Olimpio: Attentional bias in non-problem gamblers, problem gamblers, and abstinent pathological gamblers: An experimental study. J Affect Disord 2016; 13:9-16

12. Compton WM, Dawson DA, Goldstein RB \& Grant BF: Crosswalk between DSM-IV-TR dependence and DSM-5 substance use disorders for opioids, cannabis, cocaine and alcohol. Drug Alcohol Depend 2013; 132:387-90

13. Cowlishaw S, Merkouris S, Chapman A \& Radermacher $H$ : Pathological and problem gambling in substance use treatment: a systematic review and meta-analysis. $J$ Subst Abuse Treat 2014; 46:98-105

14. Daeppen JB, Yersin B, Landry U, Pécoud A \& Decrey H: Reliability and Validity of the Alcohol Use Disorders Identification Test (AUDIT) Imbedded Within a General Health Risk Screening Questionnaire: Results of a Survey in 332 Primary Care Patients. Alcohol Clin Exp Res 2000; 24:659-65

15. Dodig D, Ricijaš $N$ \& Rajić-Stojanović A: Sports betting of students in Zagreb - the contribution of irrational beliefs, motivation and experiences in games of chance (Sportsko kladenje studenata u Zagrebu - doprinos uvjerenja o kockanju, motivacije i iskustva u igrama na sreću). Ljetopis socijalnog rada 2014; 21:215-42

16. Dowling NA, Cowlishaw S, Jackson AC, Merkouris SS, Francis KL \& Christensen DR: Prevalence of psychiatric co-morbidity in treatment-seeking problem gamblers: $A$ systematic review and meta-analysis. Aust $N Z J$ Psychiatry 2015; 49:519-39

17. El-Guebaly N: Epidemiological association between gambling behaviour, substance use \& mood and anxiety disorders. J Gamble Stud 2006; 22:275-87

18. Finney JW, Hahn AC\& Moos RH: The effectiveness of inpatient and outpatient treatment for alcohol abuse: The need to focus on mediators and moderators of setting effects. Addiction 1996; 91:1773-96

19. Glavak Tkalić, R, Miletić, GM: Playing Games of Chance in General Population in the Republic of Croatia - Research Report. Institute of Social Sciences Ivo Pilar. Zagreb 2012

20. Grant B, Dawson DA, Chou SP, Ruan WJ, Pickering RP, et al: Co-occurrence of 12-month alcohol and drug use disorders and personality disorders in the United States. Arch Gen Psychiatry 2004; 61:361-8

21. Grant JE, Williams KA, \& Kim SW: Update on pathological gambling. Curr Psychiatry Rep 2006; 8:53-8

22. Hasin DS, O'Brien CP, Auriacombe M, Borges G, Bucholz $K$, Budney A, et al: DSM-5 criteria for substance use disorders: Recommendations and rationale. Am J Psychiatry 2013; 170:834-51

23. Hodgins DC, Stea JN \& Grant JE: Gambling disorders. Lancet 2011; 378:1874-84

24. Jauregui P, Estévez A \& Urbiola I: Pathological Gambling and Associated Drug and Alcohol Abuse, Emotion Regulation, and Anxious-Depressive Symptomatology. J Behav Addict 2016; 5:251-60

25. Kausch O: Patterns of substance abuse among treatmentseeking pathological gamblers. J Subst Abuse Treat 2003; 25:263-70

26. Kessler RC, Hwang I, LaBrie R, Petukhova M, Sampson $N A$, Winters $K C$ et al: The prevalence and correlates of DSM-IV pathological gambling in the National Comorbidity Survey Replication. Psychol Med 2008; 38:1351-60
27. Lesieur HR, Blume SB \& Zoppa RM: Alcoholism, drug abuse, and gambling. Alcohol Clin Exp Res 1986; 10:338

28. Lorains F, Cowlishaw S\& Thomas SA: Prevalence of comorbid disorders in problem and pathological gambling: Systematic review and meta-analysis of population surveys. Addiction 2011; 106:490-8

29. Mann K, Hintz T \& Jung M: Does psychiatric comorbidity in alcohol-dependent patients affect treatment outcome? Eur Arch Psychiatry Clin Neurosci 2004; 254:172-81

30. Marazziti D, Picchetti M, Baroni S, Consoli G, Ceresoli $D$, Massimetti G et al: Pathological gambling and impulsivity: an Italian study. Riv Psichiatr 2014; 49:95-9

31. Petry NM: Pathological gambling: Aetiology, comorbidity, and treatment. Washington, DC, American Psychological Association, 2005

32. Petry NM, Stinson FS \& Grant BF: Comorbidity of DSM$I V$ pathological gambling and other psychiatric disorders: results from the National Epidemiological Survey on Alcohol and Related Conditions. J Clin Psychiatry 2005; 66:564-74

33. Ricijaš N, Dodig D, Huić A \& Kranželić V: Habits and characteristics of adolescent gambling in urban areas research report on results (Navike i obilježja kockanja adolescenata u urbanim sredinama - izvještaj o rezultatima istraživanja). Edukacijsko-rehabilitacijski fakultet Sveučilišta u Zagrebu, 2011

34. Ricijaš N, Dodig-Hundrić D, Kranželić V: Sports Betting and Other Risk Behaviour among Croatian High-School Students (Sportsko klađenje $i$ druga rizična ponašanja hrvatskih srednjoškolaca). Hrvatska revija za rehabilitacijska istraživanja 2015; 51:41-56

35. Ricijaš $N \&$ Milun T: Mathematics of gambling and characteristics of gambling activities. In Ricijaš $N$, Kranželić $V$ \& Dodig Hundrić D (eds.): Manual for implementation of youth gambling prevention program „Who really wins?", 53-64. Faculty of Education and Rehabilitation Sciences, University of Zagreb, Zagreb, in print

36. Rumpf HJ, Hapke U, Meyer C \& John U: Screening for alcohol use disorders and at risk drinking in the general population: Psychometric performance of three questionnaires. Alcohol Alcoholism 2002; 37:261-8

37. Sanchez-Pena JF, Alvarez-Cotoli P \& Rodriguez-Solano JJ: Psychiatric disorders associated with alcoholism: 2year follow-up of treatment. Actas Esp Psiquiatr 2012; 40:129-35

38. Saunders JB, Aasland OG, Babor TF, de la Fuente JR \& Grant M: Development of the Alcohol Use Disorders Identification Test (AUDIT): WHO Collaborative Project on Early Detection of Persons with Harmful Alcohol Consumption--II. Addiction 1993; 88:791-804

39. Sellman JD, Adamson $S$, Robertson P, Sullivan $S \&$ Coverdale J: Gambling in mild-moderate alcohol-dependent outpatients. Subst Use Misuse 2002; 37:199-213

40. Shaffer HJ, LaPlante DA, LaBrie RA, Kidman RC, Donato $A N$ \& Stanton MV: Toward a syndrome model of addiction: Multiple expressions, commom etiology. Harvard Rev Psychiat 2004; 12:367-74

41. Slutske WS, Eisen SA, True WR, Lyons MJ, Goldberg J \& Tsuang MT: Common genetic vulnerability for pathological gambling and alcohol dependence in men. Arch Gen Psychiatry 2000; 57:666-73 
42. Spunt B, Lesieur H, Liberty HJ \& Hunt D: Pathological gamblers in methadone treatment: A comparison between men and women. J Gambl Stud 1996; 12:431-49

43. Stinchfield $R:$ Reliability, validity, and classification accuracy of the South Oaks gambling screen (SOGS). Addict Behav 2002; 27:1-19

44. Stinchfield R: Reliability, validity, and classification accuracy of a measure of DSM-IV diagnostic criteria for pathological gambling. Am J Psychiatry 2003; 160:180-2

45. Welte J, Barnes G, Wieczorek W, Tidwell MC \& Parker J: Alcohol and gambling pathology among US adults: Prevalence, demographic patterns and comorbidity. J Stud Alcohol 2001; 62:706-12
46. Winters $K C \&$ \& Kushner MG: Treatment issues pertaining to pathological gamblers with a comorbid disorder. J Gambl Stud 2003; 19:261-77

47. World Health Organisation: International Statistical Classification of Diseases and Related Problems. Tenth Revision. WHO, Geneva, 1992

48. World Health Organization: Global Status Report on Alcohol and Health. WHO, Geneva, 2014

49. Wüstoff L, Waal H, Ruud T \& Grawe R: A cross-sectional study of patients with and without substance use disorders in Community Mental Health Centres. BMC Psychiatry 2011; 11:93

Correspondence:

Davor Bodor, MD

Psychiatric Hospital "Sveti Ivan"

Jankomir 11, 10090 Zagreb, Croatia

E-mail:davor.bodor@pbsvi.hr 